\title{
Angiotensin converting enzyme inhibitors versus angiotensin II type 1 receptor blockers in patients with acute myocardial infarction and prediabetes after successful implantation of newer-generation drug-eluting stents
}

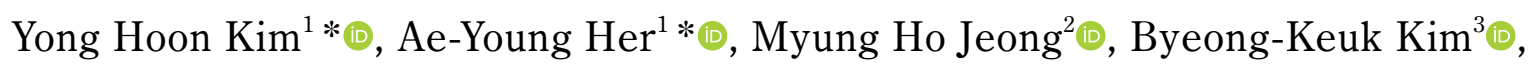
Sung-Jin Hong ${ }^{3} \mathbb{D}$, Sang-Ho Park ${ }^{4}$, Seunghwan $\mathrm{Kim}^{5}{ }^{\circledR}$, Chul-Min $\mathrm{Ahn}^{3}{ }^{\circledR}$, Jung-Sun $\mathrm{Kim}^{3}{ }^{\oplus}$, Young-Guk $\mathrm{Ko}^{3}{ }^{\oplus}$, Donghoon $\mathrm{Choi}^{3}{ }^{\oplus}$, Myeong-Ki Hong ${ }^{3} \oplus$, Yangsoo Jang ${ }^{3}$

${ }^{1}$ Division of Cardiology, Department of Internal Medicine, Kangwon National University

School of Medicine, Chuncheon, Republic of Korea

${ }^{2}$ Department of Cardiology, Cardiovascular Center, Chonnam National University Hospital, Gwangju, Republic of Korea

${ }^{3}$ Division of Cardiology, Severance Cardiovascular Hospital,

Yonsei University College of Medicine, Seoul, Republic of Korea

${ }^{4}$ Cardiology Department, Soonchunhyang University Cheonan Hospital, Cheonan, Republic of Korea

${ }^{5}$ Division of Cardiology, Inje University College of Medicine,

Haeundae Paik Hospital, Busan, Republic of Korea

\begin{abstract}
Background: Because limited data are available, the present study investigated 2-year major clinical outcomes after angiotensin-converting enzyme inhibitors (ACEIs) and angiotensin II type 1 receptor blockers (ARBs) therapy in patients with acute myocardial infarction (AMI) and prediabetes after successful implantation of newer-generation drug-eluting stents (DESs).

Methods: Overall, 2932 patients with AMI and prediabetes were classified into two groups - the ACEIs group ( $n=2059)$ and the ARBs group $(n=873)$. The primary endpoint was the occurrence of patient-oriented composite outcome (POCO), defined as all-cause death, recurrent myocardial infarction (Re-MI), or any repeat revascularization. The secondary endpoint was definite or probable stent thrombosis (ST).

Results: The cumulative incidences of POCO (adjusted hazard ratio [aHR]: 1.020; 95\% confidence interval [CI]: 0.740-1.404; $p=0.906$ ), all-cause death (aHR: 1.394; 95\% CI: 0.803-2.419; $p=0.238$ ), Re-MI (aHR: 1.210; 95\% CI: 0.626-2.340; $p=0.570$ ), any repeat revascularization ( $a H R: 1.150 ; 95 \%$ CI: $0.713-1.855 ; p=0.568)$, and ST (aHR: 1.736 ; 95\% CI: 0.445-6.766; $p=0.427$ ) were similar between the groups. These results were confirmed after propensity score-adjusted analysis.

Conclusions: In this study, patients with AMI and prediabetes who received ACEIs or ARBs showed comparable clinical outcomes during the 2-year follow-up period. (Cardiol J)
\end{abstract}

Key words: angiotensin-converting enzyme inhibitor, angiotensin receptor blocker, myocardial infarction, prediabetes, outcomes

Address for correspondence: Yong Hoon Kim, MD, PhD, Division of Cardiology, Department of Internal Medicine, Kangwon National University School of Medicine, 24289, 156 Baengnyeong Road, Chuncheon City, Gangwon Province, Republic of Korea, tel: +82-33-258-9455, fax: +82-33-258-2455, e-mail: yhkim02@kangwon.ac.kr

Received: 16.03.2021 Accepted: 25.08.2021 Early publication date: 30.09.2021

*The first two authors (Yong Hoon Kim and Ae-Young Her) have equally contributed to this work.

This article is available in open access under Creative Common Attribution-Non-Commercial-No Derivatives 4.0 International (CC BY-NC-ND 4.0) license, allowing to download articles and share them with others as long as they credit the authors and the publisher, but without permission to change them in any way or use them commercially. 


\section{Introduction}

Higher fasting glucose levels on admission are related to worse clinical outcomes regardless of the presence or absence of diabetes [1,2]. Huang et al. [3] reported that prediabetes was associated with an increased risk of composite cardiovascular disease, coronary heart disease, and all-cause mortality compared with normoglycemia. Although the exact underlying mechanism between prediabetes and increased mortality is not well known, a higher prevalence of cardiac autonomic dysfunction in prediabetes was suggested [4]. Impaired endothelial function and increased oxidative stress at the vessel wall led to activation of platelets, inflammation, and thrombosis in patients with undiagnosed diabetes or prediabetes [5]. Moreover, hyperglycemia has been linked to an increase in plasma renin activity with renin-angiotensin system (RAS) activation, which is known to impair insulin signaling [6].

Renin-angiotensin system inhibitors (RASIs) have been shown to have diverse beneficial effects on cardiovascular outcomes through the enhancement of endothelial function, cardiovascular remodeling, and progression of atherosclerosis $[7,8]$, and have positive roles in delaying or preventing the onset of diabetes mellitus (DM) [9]. The current guidelines recommend that angiotensin-converting enzyme inhibitors (ACEIs) should be used as the first-line choice of RASIs after acute myocardial infarction (AMI) and angiotensin II type 1 receptor blockers (ARBs) should be considered in patients who are intolerant to ACEIs therapy [10-13]. However, the relative superiority of ACEIs and ARBs in AMI patients with regards to long-term clinical outcomes is still debatable [14, 15]. Choi et al. [16] reported that ACEIs or ARBs have similar effects on reducing death, recurrent myocardial infarction (Re-MI), revascularization, and major adverse cardiac events in ST-segment elevation myocardial infarction (STEMI) patients with diabetes. More recently, one meta-analysis [17] suggested that ACEIs was preferred than ARBs in patients with hypertension and type 2 diabetes (T2DM). However, very limited data are available comparing the long-term major clinical outcomes between ACEIs and ARBs therapy in AMI patients with prediabetes. Hence, we investigated the 2 -year clinical outcomes following ACEIs and ARBs therapy in AMI patients with prediabetes after new-generation drug-eluting stents (DESs) implantation.

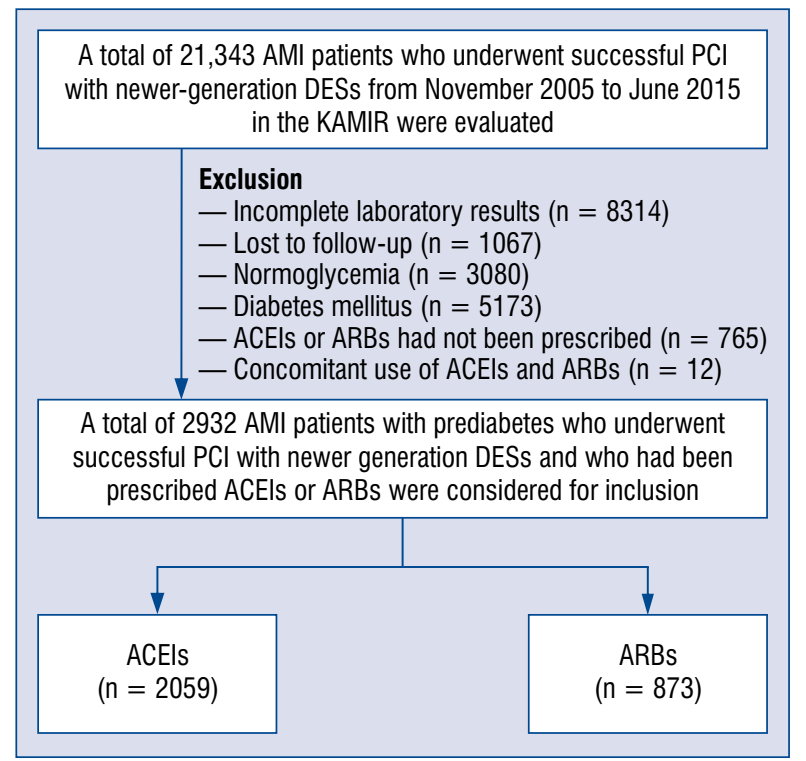

Figure 1. Flow chart; ACEls - angiotensin converting enzyme inhibitor; AMI - acute myocardial infarction; ARBs - angiotensin II type I receptor blockers; DESs - drug eluting stents; KAMIR - Korea AMI Registry; $\mathrm{PCl}$ - percutaneous coronary intervention

\section{Methods}

\section{Study population}

This study enrolled patients from the Korea AMI Registry (KAMIR) [18]. A total of 21,343 patients with AMI who underwent successful percutaneous coronary intervention (PCI) with newer-generation DESs from November 2005 to June 2015 were evaluated in this retrospective cohort study. Among them, patients with incomplete laboratory results $(\mathrm{n}=8314,39.0 \%)$, those who were lost to follow-up $(n=1067,5 \%)$, those with normoglycemia $(n=3080,14.4 \%)$, those with $\mathrm{DM}$ $(\mathrm{n}=5173,24.2 \%)$, those who were not prescribed ACEIs or ARBs ( $\mathrm{n}=765,3.6 \%$ ), and those who were concomitantly using ACEIs and ARBs $(n=12$, $0.1 \%$ ) were excluded. Finally, a total of 2932 patients with AMI who underwent successful implantation of newer-generation DESs and who had been prescribed ACEs or ARBs were considered for inclusion. These patients were divided into two groups - the ACEIs group $(\mathrm{n}=2059,70.2 \%)$ and the ARBs group ( $\mathrm{n}=873,29.8 \%$ ) (Fig. 1). This study protocol was approved by the ethics committee at each participating center and the Chonnam National University Hospital Institutional Review Board ethics committee (CNUH-2011-172) accord- 
ing to the ethical guidelines of the 1975 Declaration of Helsinki. All patients provided written informed consent prior to enrollment, and they completed a 2-year clinical follow-up through face-to-face interviews, phone calls, and chart reviews. Additionally, all clinical events were evaluated by an independent event adjudicating committee. The process off event adjudicating is described in the previous publication by KAMIR investigators [18].

\section{Percutaneous coronary intervention procedures and medical treatment}

Percutaneous coronary intervention was performed using the standard technique [19]. Before PCI, all patients received loading doses of acetylsalicylic acid (ASA; 200-300 mg) and other antiplatelet agents, including clopidogrel, ticagrelor, or prasugrel. After the index PCI, dual antiplatelet therapy (DAPT; a combination of ASA $100 \mathrm{mg} /$ /day with clopidogrel $75 \mathrm{mg} /$ day or ticagrelor $90 \mathrm{mg}$ twice daily or prasugrel $5-10 \mathrm{mg} /$ day) was recommended for at least 1 year. The use of triple antiplatelet therapy (cilostazol $100 \mathrm{mg}$ twice daily added to DAPT) was left to the discretion of the individual operators. The kinds and doses of ACEIs or ARBs were as follows; $12.5-75 \mathrm{mg}$ of captopril, 1.25-10 mg of ramipril, 2.5-10 mg of perindopril, 1.25$-5 \mathrm{mg}$ of cilazapril, $5-10 \mathrm{mg}$ of imidapril, $7.5-30 \mathrm{mg}$ of moexipril, $2.5-10 \mathrm{mg}$ of enalapril, $5-10 \mathrm{mg}$ of lisinopril, $10 \mathrm{mg}$ of fosinopril, $3.75-7.5 \mathrm{mg}$ of zofenopril, 25-100 mg of losartan, 150-300 mg of irbesartan, $40-160 \mathrm{mg}$ of valsartan, $40-80 \mathrm{mg}$ of telmisartan, 10-20 $\mathrm{mg}$ of olmesartan, 4-32 $\mathrm{mg}$ of candesartan, $600 \mathrm{mg}$ of eprosartan, and 15-60 mg of fimasartan per day.

\section{Study definitions and clinical outcomes}

Glycemic status of the enrolled patients was estimated based on medical history and glycated hemoglobin $\left(\mathrm{HbA}_{1 \mathrm{c}}\right)$ and fasting plasma glucose (FPG) levels at the index hospitalization. According to the definition of the American Diabetes Association [20], prediabetes was defined as an $\mathrm{HbA}_{1 \mathrm{c}}$ of $5.7-6.4 \%$ and an FPG of $100-125 \mathrm{mg} / \mathrm{dL}$ $(5.6-6.9 \mathrm{mmol} / \mathrm{L})$. The definitions of STEMI and non-STEMI (NSTEMI) were defined by the current guidelines $[11,13]$. An early invasive treatment strategy of the patients with NSTEMI was defined as PCI within 24 hours after admission [13]. A successful PCI was defined as a residual stenosis less than $30 \%$ and thrombolysis in myocardial infarction grade 3 flow for the infarct-related artery (IRA) after the procedure. The primary endpoint of this study was the occurrence of patient-oriented com- posite outcomes (POCO) composed of all-cause death, Re-MI, or any coronary repeat revascularization [21]. The secondary endpoint was definite or probable stent thrombosis (ST) during the 2-year follow-up period. All-cause death was classified as cardiac death (CD) or non-CD. The definitions of any repeat revascularization, Re-MI were previously reported [22]. The cumulative incidence of ST was defined by the current consensus [23].

\section{Statistical analysis}

Categorical data are reported as numbers and percentages, and were compared using the $\chi^{2}$ or Fisher's exact test as appropriate. Continuous variables are expressed as mean \pm standard deviation and were compared using Student's $\mathrm{t}$-test. Any variables with a $\mathrm{p}$ value of $<0.001$ in the univariate analysis and conventional risk factors of poor outcomes in the AMI population were considered potential confounding factors, and were entered into the multivariate analysis. This included age, left ventricular ejection fraction (LVEF), STEMI, NSTEMI, hypertension, current smokers, clopidogrel, ticagrelor, beta-blockers (BBs), American College of Cardiology/American Heart Association (ACC/AHA) type B2 and C lesion, one-vessel disease, and stent diameter. Various clinical outcomes were estimated using the Kaplan-Meier curve analysis, and differences between the groups were compared using the log-rank test. For all analyses, two-sided p values $<0.05$ were considered statistically significant. In addition, to adjust for any potential confounders, a propensity-score (PS) adjusted analysis was performed using a logistic regression model (Suppl. Material 1). All available variables listed in Table 1 that could be of potential relevance were tested. The PS was estimated using a C-statistic for the logistic regression model and the PS for the two groups was 0.718 . Proportional hazard models were used to assess the hazard ratio (HR) of the ARBs group compared with the ACEIs group adjusted PS. All statistical analyses were performed using SPSS software, version 20 (IBM; Armonk, NY, USA).

\section{Results}

\section{Baseline characteristics}

Table 1 shows the baseline characteristics of the study population. The mean age of patients in the ARBs group was greater than the mean age of the patients in the ACEIs group $(64.4 \pm 12.2$ years vs. $62.2 \pm 12.4$ years; $\mathrm{p}<0.001)$. The mean value of $\operatorname{LVEF}(54.6 \pm 10.8 \%$ vs. $52.4 \pm 10.5 \%$; 
Table 1. Baseline clinical, laboratory, angiographic, and procedural characteristics.

\begin{tabular}{|c|c|c|c|c|c|}
\hline Variables & Total $(n=2932)$ & ACEls $(n=2059)$ & ARBs $(n=873)$ & $\mathbf{P}$ & SD \\
\hline Age [years] & $62.9 \pm 12.4$ & $62.2 \pm 12.4$ & $64.4 \pm 12.2$ & $<0.001$ & -1.79 \\
\hline Men & $2243(76.5 \%)$ & $1609(78.1 \%)$ & $634(72.6 \%)$ & 0.001 & 1.71 \\
\hline LVEF [\%] & $53.1 \pm 10.6$ & $52.4 \pm 10.5$ & $54.6 \pm 10.8$ & $<0.001$ & -2.07 \\
\hline BMI $\left[\mathrm{kg} / \mathrm{m}^{2}\right]$ & $24.3 \pm 3.2$ & $24.3 \pm 3.1$ & $24.2 \pm 3.2$ & 0.575 & 0.32 \\
\hline $\mathrm{SBP}[\mathrm{mmHg}]$ & $131.1 \pm 27.3$ & $131.0 \pm 27.2$ & $131.3 \pm 27.5$ & 0.798 & -0.10 \\
\hline $\mathrm{DBP}[\mathrm{mmHg}]$ & $79.8 \pm 16.2$ & $79.6 \pm 16.3$ & $80.3 \pm 16.2$ & 0.304 & -0.43 \\
\hline STEMI & $1759(60 \%)$ & $1281(62.2 \%)$ & $478(54.8 \%)$ & $<0.001$ & 2.01 \\
\hline Primary $\mathrm{PCl}$ & $1702 / 1759(96.8 \%)$ & $1237 / 1281(96.6 \%)$ & $465 / 478(97.3 \%)$ & 0.451 & -0.38 \\
\hline NSTEMI & $1173(40.0 \%)$ & $778(37.8 \%)$ & $395(45.2 \%)$ & $<0.001$ & -2.01 \\
\hline $\mathrm{PCl}$ within $24 \mathrm{~h}$ & $1020 / 1173(87.0 \%)$ & $675 / 778(86.8 \%)$ & $345 / 395(87.3 \%)$ & 0.727 & -0.18 \\
\hline Cardiogenic shock & $117(4.0 \%)$ & $88(4.3 \%)$ & $29(3.3 \%)$ & 0.257 & 0.51 \\
\hline CPR on admission & $113(3.9 \%)$ & $68(3.3 \%)$ & $45(5.2 \%)$ & 0.017 & -1.02 \\
\hline Hypertension & $1286(43.9 \%)$ & $853(41.4 \%)$ & $433(49.6 \%)$ & $<0.001$ & -2.19 \\
\hline Dyslipidemia & $329(11.2 \%)$ & $239(11.6 \%)$ & $90(10.3 \%)$ & 0.308 & 0.49 \\
\hline Previous MI & $70(2.4 \%)$ & 39 (1.9\%) & $31(3.6 \%)$ & 0.007 & -1.02 \\
\hline Previous PCl & $135(4.6 \%)$ & $78(3.8 \%)$ & $57(6.5 \%)$ & 0.001 & -1.41 \\
\hline Previous CABG & $5(0.2 \%)$ & $1(0.0 \%)$ & $4(0.5 \%)$ & 0.030 & -0.83 \\
\hline Previous HF & $22(0.8 \%)$ & $12(0.6 \%)$ & $10(1.1 \%)$ & 0.157 & -0.34 \\
\hline Previous CVA & $139(4.7 \%)$ & $94(4.6 \%)$ & $45(5.2 \%)$ & 0.492 & -0.30 \\
\hline Current smokers & $1398(47.7 \%)$ & $1030(50.0 \%)$ & $368(42.2 \%)$ & $<0.001$ & 2.06 \\
\hline Peak CK-MB [mg/dL] & $142.8 \pm 202.1$ & $148.4 \pm 217.1$ & $129.5 \pm 160.5$ & 0.020 & 0.99 \\
\hline Peak troponin-I [ng/mL] & $48.0 \pm 117.8$ & $49.1 \pm 133.7$ & $45.5 \pm 66.6$ & 0.451 & 0.34 \\
\hline NT-proBNP [pg/mL] & $1143.7 \pm 2088.6$ & $1069.6 \pm 2024.4$ & $1318.4 \pm 2224.3$ & 0.003 & -1.17 \\
\hline hs-CRP [mg/dL] & $8.8 \pm 48.6$ & $7.8 \pm 32.6$ & $11.4 \pm 73.6$ & 0.066 & -0.63 \\
\hline Serum creatinine $[\mathrm{mg} / \mathrm{L}]$ & $1.01 \pm 0.98$ & $0.99 \pm 0.82$ & $1.05 \pm 1.25$ & 0.220 & -0.57 \\
\hline eGFR $\left[\mathrm{mL} / \mathrm{min} / 1.73 \mathrm{~m}^{2}\right]$ & $90.2 \pm 40.2$ & $89.5 \pm 36.7$ & $91.8 \pm 42.3$ & 0.161 & -0.58 \\
\hline Blood glucose [mg/dL] & $146.0 \pm 45.4$ & $146.2 \pm 44.5$ & $145.6 \pm 47.4$ & 0.754 & 0.13 \\
\hline Hemoglobin A1c [\%] & $5.96 \pm 0.21$ & $5.95 \pm 0.21$ & $5.96 \pm 0.22$ & 0.426 & -0.47 \\
\hline Total cholesterol [mg/dL] & $190.5 \pm 42.4$ & $191.7 \pm 42.6$ & $187.7 \pm 41.7$ & 0.019 & 0.95 \\
\hline Triglyceride $[\mathrm{mg} / \mathrm{L}]$ & $136.3 \pm 107.7$ & $135.8 \pm 105.1$ & $137.4 \pm 113.6$ & 0.718 & -0.15 \\
\hline HDL cholesterol [mg/L] & $43.9 \pm 15.4$ & $44.1 \pm 15.9$ & $43.5 \pm 14.0$ & 0.341 & 0.40 \\
\hline LDL cholesterol [mg/L] & $122.6 \pm 48.0$ & $122.4 \pm 37.1$ & $123.0 \pm 67.0$ & 0.781 & -0.11 \\
\hline \multicolumn{6}{|l|}{ Discharge medications: } \\
\hline Acetylsalicylic acid & $2918(99.5 \%)$ & $2048(99.5 \%)$ & $870(99.7 \%)$ & 0.494 & -0.14 \\
\hline Clopidogrel & $2513(85.7 \%)$ & $1797(87.3 \%)$ & $716(82.0 \%)$ & $<0.001$ & 1.95 \\
\hline Ticagrelor & $266(9.1 \%)$ & $162(7.9 \%)$ & $104(11.9 \%)$ & $<0.001$ & -1.71 \\
\hline Prasugrel & $137(4.7 \%)$ & $93(4.5 \%)$ & $44(5.0 \%)$ & 0.539 & -0.25 \\
\hline Cilostazole & $566(19.3 \%)$ & $406(19.7 \%)$ & $160(18.3 \%)$ & 0.383 & 0.45 \\
\hline Beta-blockers & $2591(88.4 \%)$ & $1849(89.8 \%)$ & $742(85.0 \%)$ & $<0.001$ & 1.89 \\
\hline CCBs & $147(5.0 \%)$ & $88(4.3 \%)$ & $59(6.8 \%)$ & 0.005 & -1.27 \\
\hline Lipid lowering agent & $2653(90.5 \%)$ & $1867(90.7 \%)$ & $786(90.0 \%)$ & 0.589 & 0.28 \\
\hline \multicolumn{6}{|c|}{ Angiographic and procedural characteristics } \\
\hline \multicolumn{6}{|c|}{ Infarct-related artery: } \\
\hline Left main & $36(1.2 \%)$ & $17(0.8 \%)$ & $19(2.2 \%)$ & 0.002 & -0.94 \\
\hline Left anterior descending & $1474(50.2 \%)$ & $1060(51.5 \%)$ & $414(47.4 \%)$ & 0.044 & 1.08 \\
\hline Left circumflex & $494(16.8 \%)$ & $338(16.4 \%)$ & $156(17.9 \%)$ & 0.320 & -0.51 \\
\hline Right coronary artery & $928(31.7 \%)$ & $644(31.3 \%)$ & $284(32.5 \%)$ & 0.504 & -0.34 \\
\hline
\end{tabular}


Table 1 (cont.). Baseline clinical, laboratory, angiographic, and procedural characteristics.

\begin{tabular}{|c|c|c|c|c|c|}
\hline Variables & Total $(n=2932)$ & ACEIs $(n=2059)$ & ARBs $(n=873)$ & $\mathbf{P}$ & SD \\
\hline \multicolumn{6}{|l|}{ Treated vessel: } \\
\hline Left main & $72(2.5 \%)$ & $39(1.9 \%)$ & $33(3.8 \%)$ & 0.003 & -1.14 \\
\hline Left anterior descending & $1753(59.8 \%)$ & $1249(60.7 \%)$ & $504(57.7 \%)$ & 0.139 & 0.80 \\
\hline Left circumflex & $754(25.7 \%)$ & $511(24.8 \%)$ & $243(27.8 \%)$ & 0.087 & -0.90 \\
\hline Right coronary artery & $1114(38.0 \%)$ & $759(36.9 \%)$ & $355(40.7 \%)$ & 0.052 & -1.04 \\
\hline \multicolumn{6}{|l|}{ ACC/AHA lesion type: } \\
\hline Type B1 & $398(13.6 \%)$ & $287(13.9 \%)$ & $111(12.7 \%)$ & 0.376 & 0.43 \\
\hline Type B2 & $958(32.7 \%)$ & $599(29.1 \%)$ & $359(41.1 \%)$ & $<0.001$ & -3.44 \\
\hline Type C & $1288(43.9 \%)$ & $989(48.0 \%)$ & $299(34.2 \%)$ & $<0.001$ & 3.65 \\
\hline \multicolumn{6}{|l|}{ Extent of CAD: } \\
\hline One-vessel & $1547(52.8 \%)$ & $1058(51.4 \%)$ & $489(56.0 \%)$ & 0.019 & -1.22 \\
\hline Two-vessel & $897(30.6 \%)$ & $652(31.7 \%)$ & $245(28.1 \%)$ & 0.214 & 1.01 \\
\hline$\geq$ Three-vessel & $488(16.6 \%)$ & $349(16.9 \%)$ & $139(15.9 \%)$ & 0.494 & 0.34 \\
\hline \multicolumn{6}{|l|}{ Drug-eluting stents: } \\
\hline ZES & $1006(34.3 \%)$ & $707(34.3 \%)$ & $299(34.2 \%)$ & 0.964 & 0.03 \\
\hline EES & $1533(52.3 \%)$ & $1080(52.5 \%)$ & $453(51.9 \%)$ & 0.553 & 0.16 \\
\hline BES & $393(13.4 \%)$ & $272(13.2 \%)$ & $121(13.9 \%)$ & 0.637 & -0.25 \\
\hline IVUS & $707(24.1 \%)$ & $494(24.0 \%)$ & $213(24.4 \%)$ & 0.814 & -0.12 \\
\hline OCT & $27(0.9 \%)$ & $23(1.1 \%)$ & $4(0.5 \%)$ & 0.094 & 0.39 \\
\hline FFR & $38(1.3 \%)$ & $28(1.4 \%)$ & $10(1.1 \%)$ & 0.639 & 0.19 \\
\hline Stent diameter [mm] & $3.15 \pm 0.42$ & $3.17 \pm 0.42$ & $3.12 \pm 0.42$ & 0.007 & 1.19 \\
\hline Stent length [mm] & $26.8 \pm 11.0$ & $27.0 \pm 10.9$ & $26.2 \pm 11.2$ & 0.065 & 0.72 \\
\hline Number of stents & $1.47 \pm 0.78$ & $1.46 \pm 0.77$ & $1.51 \pm 0.81$ & 0.136 & -0.63 \\
\hline
\end{tabular}

Values are mean \pm standard deviations or number (\%). The p values for continuous data obtained from analysis of the independent sample t-test. The $p$ values for categorical data obtained from the chi-square test or Fisher's exact test. ACC/AHA - American College of Cardiology/ /American Heart Association; ACEls - angiotensin converting enzyme inhibitors; ARBs - angiotensin II type 1 receptor blockers; BES biolimus-eluting stents; BMI — body mass index; CABG — coronary artery bypass graft; CAD — coronary artery disease; CCBs — calcium channel blockers; CK-MB - creatine kinase myocardial band; CPR - cardiopulmonary resuscitation; CVA - cerebrovascular accidents; DBP — diastolic blood pressure; EES - everolimus-eluting stents; eGFR - estimated glomerular filtration rate; FFR - fractional flow reserve; $\mathrm{HDL}$ - high-density lipoprotein; HF — heart failure; hs-CRP — high sensitivity-C-reactive protein; IVUS — intravascular ultrasound; LDL — low-density lipoprotein; LVEF — left ventricular ejection fraction; MI — myocardial infarction; NSTEMI - non-STEMI; NT-proBNP - N-terminal pro-B-type natriuretic peptide; OCT — optical coherence tomography; PCI — percutaneous coronary intervention; SBP — systolic blood pressure; SD — standardized mean difference; STEMI - ST-segment elevation myocardial infarction; ZES — zotarolimus-eluting stents

$\mathrm{p}<0.001$ ) was higher in the ARBs group. The number of patients with STEMI was higher in the ACEIs group than in the ARBs group. In contrast, the number of NSTEMI patients was higher in the ARBs group. The number of current smokers, blood levels of peak level of creatine kinase myocardial band and total cholesterol, prescription rates of clopidogrel and BBs; number of left anterior descending coronary artery as an IRA and $\mathrm{ACC} / \mathrm{AHA}$ type $\mathrm{C}$ lesion, and the mean diameter of deployed stents were higher in the ACEIs group than in the ARBs group. Compared with the ACEIs group, the ARBs group had higher number of patients with cardiopulmonary resuscitation (CPR) on admission and hypertension, a previous history of heart disease (MI, PCI, and coronary artery bypass graft), a higher level of N-terminal pro-B- -type natriuretic peptide, a higher incidence of left main coronary artery as an IRA $(2.2 \%$ vs. $0.8 \%$; $\mathrm{p}=0.002)$ and a treated vessel (3.8\% vs. $1.9 \%$; $\mathrm{p}=0.003$ ), more ACC/AHA type B2 lesions, and a higher incidence of one-vessel disease. However, the number of primary PCIs performed; PCIs performed within 24 hours of admission; cardiogenic shock; the kinds of stents deployed; and the use of intravascular ultrasound; optical coherence tomography and fractional flow reserve was similar between the two groups.

\section{Clinical outcomes}

Table 2 and Figure 2 show the cumulative incidences of major clinical outcomes. Before adjustment, the cumulative incidence of $\mathrm{CD}$ was significantly higher in the ARB group than in the 


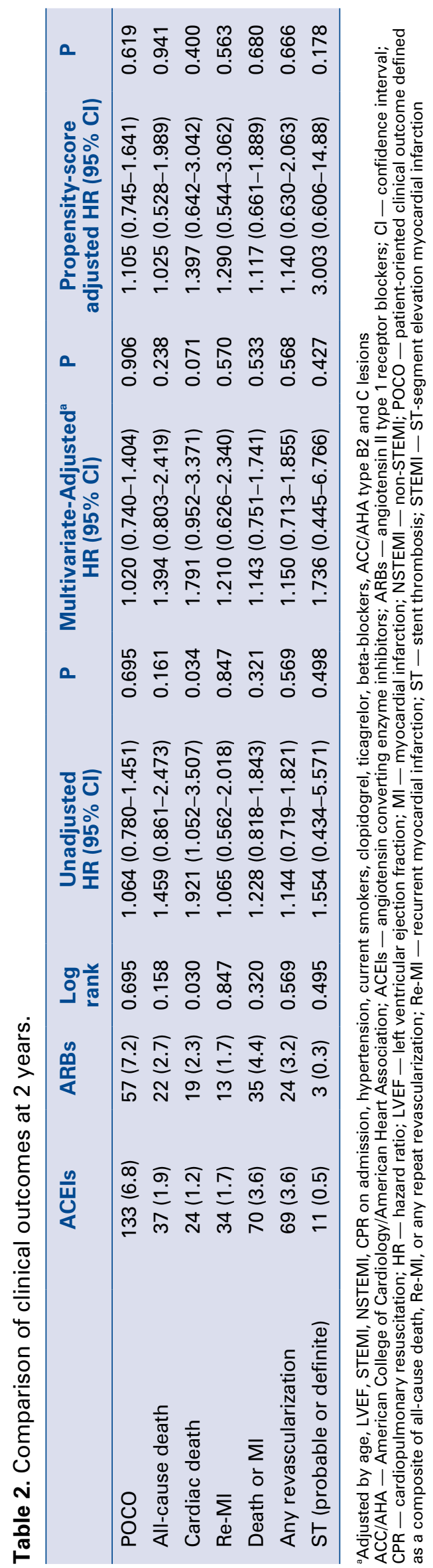

ACE group (2.3\% vs. $1.2 \%$; $=0.030$; Table 2). After adjustment, both groups had similar cumulative incidences of POCO (adjusted HR [aHR]: 1.020; 95\% confidence interval [CI]: 0.740-1.404; $\mathrm{p}=0.906$ ), all-cause death (aHR: 1.394; 95\% CI: 0.803-2.419; $\mathrm{p}=0.238$ ), CD (aHR: $1.791 ; 95 \%$ CI: $0.952-3.371 ; \mathrm{p}=0.071$ ), Re-MI (aHR: 1.210; 95\% CI: $0.626-2.340 ; \mathrm{p}=0.570$ ), death or MI (aHR: 1.143; 95\% CI: 0.751-1.741; $\mathrm{p}=0.533$ ), any repeat revascularization (aHR: $1.150 ; 95 \%$ CI: 0.713-1.855; $\mathrm{p}=0.568$ ), and ST (aHR: 1.736; 95\% CI: 0.445-6.766; $\mathrm{p}=0.427)$. Further, after PS-adjusted analysis, the cumulative incidences of POCO (aHR: 1.105; 95\% CI: 0.745-1.641; $\mathrm{p}=0.619$ ), all-cause death (aHR: 1.025; 95\% CI: $0.528-1.989 ; \mathrm{p}=0.941$ ), CD (aHR: 1.397; 95\% CI: $0.642-3.042 ; \mathrm{p}=0.400$ ), Re-MI (aHR: 1.290 ; 95\% CI: $0.544-3.062 ; \mathrm{p}=0.563$ ), death or MI (aHR: 1.117; 95\% CI: 0.661-1.889; $\mathrm{p}=0.680$ ), any repeat revascularization (aHR: $1.140 ; 95 \%$ CI: 0.630-2.063; $\mathrm{p}=0.666$ ), and ST (aHR: 3.003; 95\% CI: 0.606-14.88; $\mathrm{p}=0.178$ ) were also similar between the groups. Table 3 shows the independent predictors of POCO at 2 years. Old age ( $\geq 65$ years, aHR: 1.396; 95\% CI: 1.015-1.919; $\mathrm{p}=0.040$ ), $\mathrm{CPR}$ on admission (aHR: $2.418 ; 95 \% \mathrm{CI}$ : 1.414-4.137; $\mathrm{p}=0.001$ ), and multivessel disease (aHR: 1.656; 95\% CI: 1.226-2.238; p = 0.001) were meaningful independent predictors for POCO. The results of subgroup analysis using Cox regression model in the total study population (Fig. 3) showed that all parameters including age, sex, STEMI, CPR on admission, hypertension, BBs, ACC/AHA type $\mathrm{B} 2 / \mathrm{C}$ lesions, stent diameter, stent length, and multivessel disease were comparable between the two groups.

\section{Discussion}

The main findings of this study are: (1) the cumulative incidences of POCO, all-cause death, Re-MI, any repeat revascularization, and ST were not significantly different between the ACEI and ARB groups; and (2) old age, cardiopulmonary resuscitation on admission, and multivessel disease were independent predictors of POCO.

According to current guidelines, RASIs are recommended to improve cardiovascular outcomes in patients with AMI regardless of the presence or absence of diabetes and prediabetes, inevitably [10-13]. Therefore, it was thought that patients with AMI and prediabetes who had been prescribed ACEIs or ARBs following implantation of newergeneration DESs were considered for inclusion and 


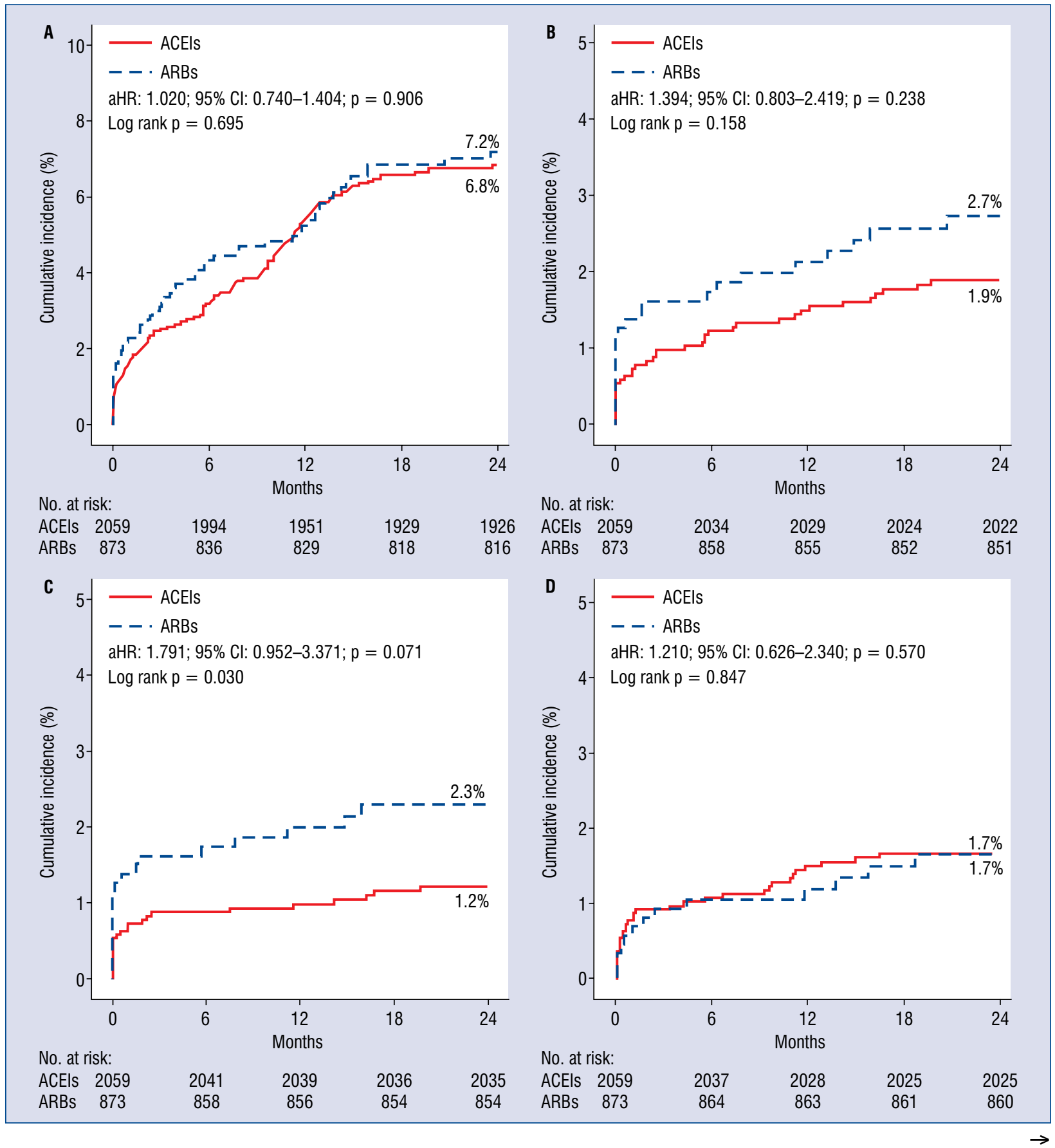

we decided to determine the relative superiority of ACEIs and ARBs during a long-term follow-up period in this study. Diverse and complex potential mechanisms underlying the protective effects of RASIs have been reported. Through their vasodilation capacity, RASIs can improve muscular blood flow and may promote insulin secretion by enhancing pancreatic blood flow [24]. In addition, RASIs can decrease sympathetic activity, improve cellular insulin action and insulin secretion by preserving cellular potassium and magnesium pools, and reduce the incidence of diabetes through direct inhibition of angiotensin and/or enhancement of bradykinin [24]. Further, as some RASIs have thiazolidinedione-like activity, which induces peroxisome proliferator-activated receptor- $\gamma$ activity, they may improve insulin sensitivity [24].

With regard to diabetes, data regarding the beneficial role of ACEIs or ARBs in patients with diabetes are controversial or uncertain [25-27]. In the DIABHYCAR (non-insulin-dependent diabetes, hypertension, microalbuminuria or proteinuria, 


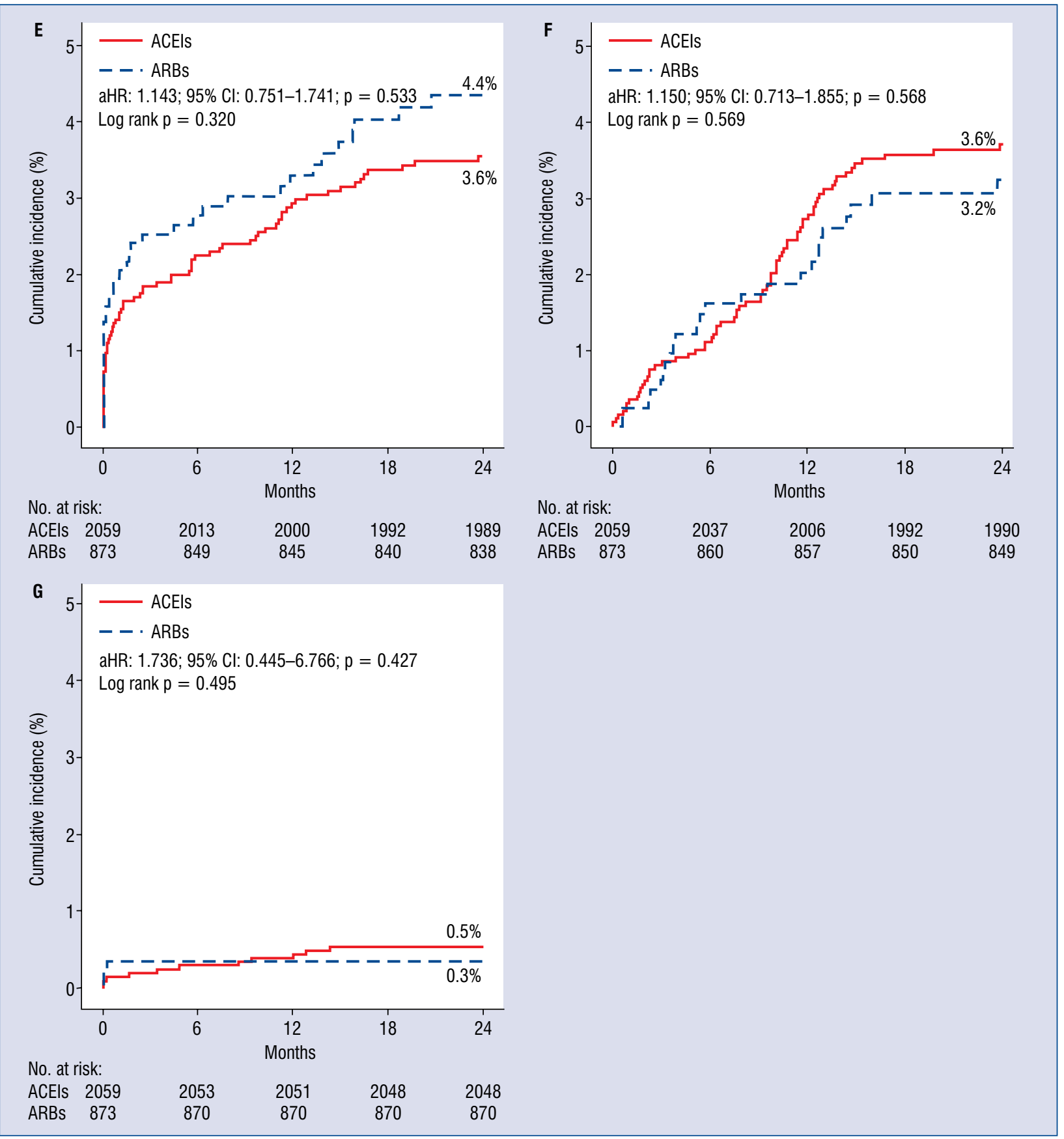

Figure 2. The Kaplan-Meier analysis for patient-oriented composite outcomes (A), all-cause death (B), cardiac death $(\mathbf{C})$, recurrent myocardial infarction (D), death or myocardial infarction $(\mathbf{E})$, any repeat revascularization $(\mathbf{F})$, and stent thrombosis (G) at 2 years; ACEls - angiotensin converting enzyme inhibitors; ARBs - angiotensin II type I receptor blockers.

cardiovascular events, and ramipril) study [27], administration of low-dose $(1.25 \mathrm{mg})$ ramipril once daily did not show any effect on cardiovascular and renal outcomes in patients with type 2 diabetes and albuminuria. Haller at al. [26] suggested that olmesartan was associated with a higher rate of fatal cardiovascular events among patients with pre-existing coronary heart disease. A meta-analysis [25] demonstrated that compared with controls, ACEIs reduced the risk of all-cause death and cardiovascular death by $13 \%$ and $17 \%$, respectively, in patients with DM during the 1-year follow-up period. However, ARBs did not significantly affect all-cause death and cardiovascular death in this meta-analysis. 
Table 3. Independent predictors for POCO.

\begin{tabular}{lcccc}
\hline Variables & $\begin{array}{c}\text { Unadjusted } \\
\text { HR (95\% CI) }\end{array}$ & P & $\begin{array}{c}\text { Adjusted } \\
\text { HR (95\% CI) }\end{array}$ & P \\
\hline ACEls vs. ARBs & $1.064(0.780-1.451)$ & 0.695 & $1.021(0.745-1.399)$ & 0.899 \\
Age, $\geq 65$ years & $1.559(1.171-2.075)$ & 0.002 & $1.396(1.015-1.919)$ & 0.040 \\
Male & $1.314(0.958-1.801)$ & 0.090 & $1.161(0.818-1.649)$ & 0.402 \\
LVEF, <40\% & $1.436(0.943-2.186)$ & 0.092 & $1.309(0.842-2.035)$ & 0.231 \\
eGFR, <60 mL/min/1.73 m & $1.320(0.903-1.931)$ & 0.152 & $1.168(0.784-1.740)$ & 0.444 \\
STEMI & $1.308(0.983-1.740)$ & 0.065 & $1.299(0.963-1.751)$ & 0.087 \\
Hypertension & $1.039(0.780-1.383)$ & 0.795 & $1.118(0.828-1.509)$ & 0.468 \\
Previous PCI & $1.048(0.537-2.047)$ & 0.897 & $1.145(0.581-2.258)$ & 0.695 \\
Cardiogenic shock & $1.349(0.714-2.551)$ & 0.357 & $1.143(0.590-2.212)$ & 0.693 \\
CPR on admission & $2.435(1.459-4.064)$ & 0.001 & $2.418(1.414-4.137)$ & 0.001 \\
LAD-IRA & $1.031(0.775-1.370)$ & 0.836 & $1.055(0.783-1.421)$ & 0.727 \\
Multivessel disease & $1.719(1.283-2.302)$ & $<0.001$ & $1.656(1.226-2.238)$ & 0.001 \\
ACC/AHA type B2/C lesion & $1.159(0.841-1.598)$ & 0.367 & $1.222(0.881-1.695)$ & 0.230 \\
Stent diameter, < 3.0 mm & $1.114(0.814-1.524)$ & 0.500 & $1.034(0.749-1.427)$ & 0.841 \\
Stent length, $\geq 28 \mathrm{~mm}$ & $1.150(0.863-1.533)$ & 0.341 & $1.066(0.794-1.432)$ & 0.669 \\
\hline
\end{tabular}

ACC/AHA - American College of Cardiology/American Heart Association; ACEls — angiotensin converting enzyme inhibitors; ARBs - angiotensin II type 1 receptor blockers; $\mathrm{Cl}$ - confidence interval; $\mathrm{CPR}$ - cardiopulmonary resuscitation; eGFR - estimated glomerular filtration rate; HR - hazard ratio; IRA — infarct-related artery; LAD — left anterior descending coronary artery; $\mathrm{PCI}$ - percutaneous coronary intervention; POCO - patient-oriented clinical outcome defined as a composite of all-cause death, Re-MI, or any repeat revascularization; STEMI -

ST-segment elevation myocardial infarction

In patients with DM and albuminuria, Wang et al. [28] showed that ARBs reduced risks of end stage renal disease and doubling of serum creatinine level. ACEIs and ARBs failed to reduce all-cause mortality and cardiovascular events. With respect to renoprotective effects, ARBs may be preferred for diabetic patients with albuminuria. Lv et al. [17] suggested that treatment with ACEIs showed a significant cardiovascular protection for all-cause mortality, cardiovascular death, and major cardiovascular events, whereas ARBs had no benefits on these outcomes except myocardial infarction.

With regard to prediabetes, limited data are available regarding the comparative long-term effects of follow-up with ACEIs and ARBs [29-31]. Zidek et al. [29] suggested that ramipril was preferable to diuretics for the management of hypertension in prediabetes, considering the prevalence of new-onset diabetes. Min et al. [30] demonstrated that angiotensin II played an important role in the development of albuminuria in patients with impaired glucose metabolism. In an animal study, Zhang et al. [31] showed that angiotensin II type 1 receptor-mediated coronary vasoconstriction is augmented in prediabetes, which may contribute to impaired coronary blood flow. This suggests that RASIs may be involved in one of the major determinants of prediabetes. Although both ACEIs and
ARBs limit the effects of angiotensin II, their mechanisms of action are not identical $[32,33]$. Compared with ACEIs, ARBs increase circulating angiotensin II levels through unwanted stimulation of the angiotensin II type 2 (AT2) receptor. Increased number of AT2 receptor is an important cause of plaque instability and thrombus formation in patients with coronary artery disease [32]. Despite these limitations of ARBs, the cumulative incidence of primary and secondary endpoints was similar between the two groups in this study. Further, these results were confirmed after PS-adjusted analysis.

According to available research, there are no studies that can be used to directly compare the results of the present study. Therefore, determining a meaningful value of this study compared to those of other studies and speculating about the main cause of the results of this study compared to those of other studies are challenging. Previous studies that compared the clinical outcomes between ACEIs and ARBs were not performed in the era of newer-generation DESs [14, 32, 34], concomitantly used newer-generation and non-newer-generation DESs [25], or also included patients with other conditions which were not confined to AMI [27, 29]. Yang et al. [35] reported that ARBs were as beneficial as ACEIs in STEMI patients with preserved LVEF after PCI. Similar 


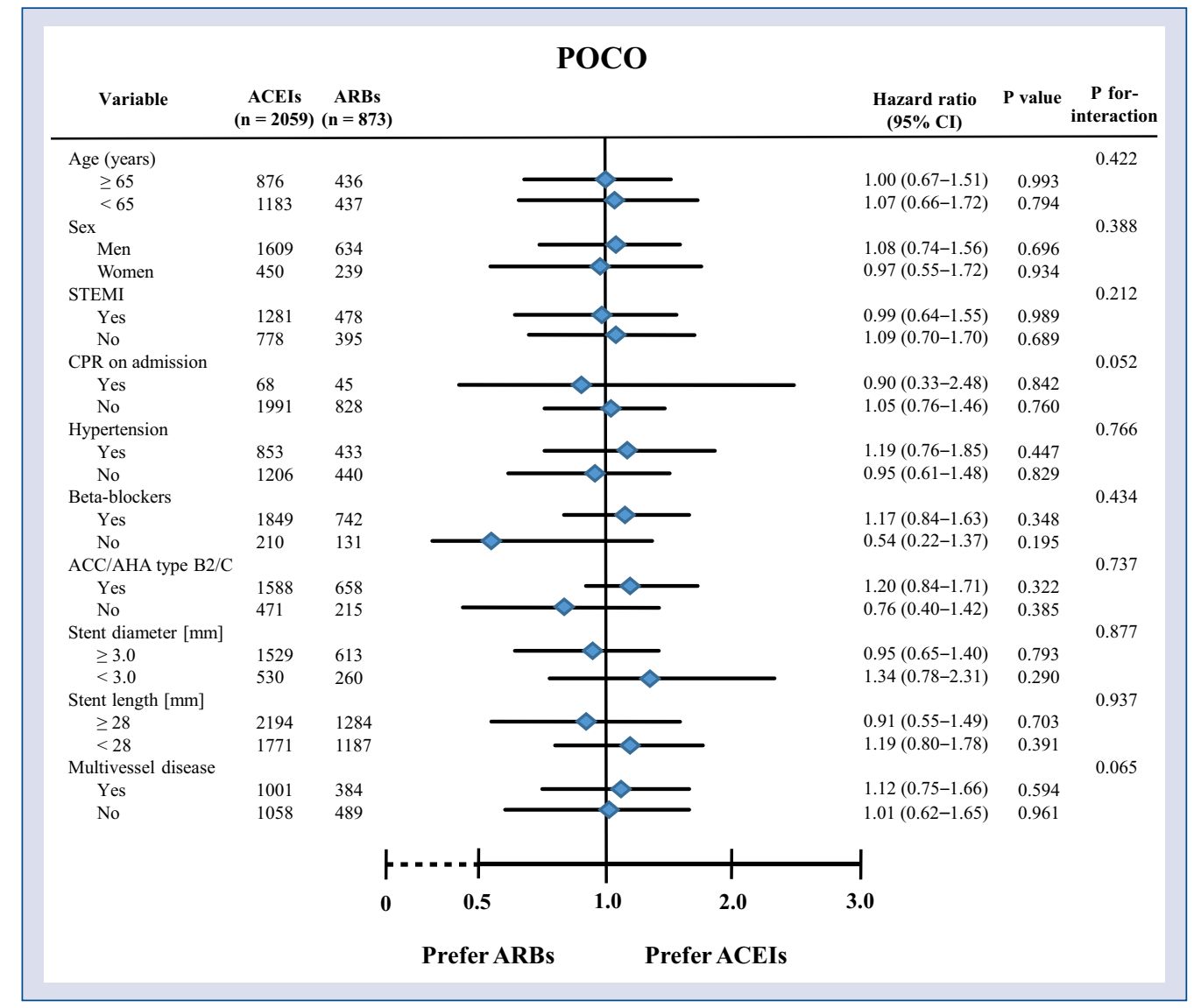

Figure 3. Subgroup analysis for patient-oriented clinical outcome defined as a composite of all-cause death (POCO), recurrent myocardial infarction, or any repeat revascularization; ACC/AHA - American College of Cardiology/American Heart Association; ACEls - angiotensin converting enzyme inhibitors; ARBs - angiotensin II type 1 receptor blockers; $\mathrm{Cl}$ - confidence interval; CPR - cardiopulmonary resuscitation; STEMI - ST-segment elevation myocardial infarction.

to the Yang et al. [35] report, the study population of this study was composed of patients who had relatively well-preserved LVEFs $(53.1 \pm 10.6 \%$, Table 1) and the number of STEMI patients was more than $50 \%$. Therefore, these baseline characteristics may be related with the similar cumulative incidences of primary and secondary endpoints between ACEIs and ARBs. In a recent large retrospective study with more than half a million patients (from the United States, Germany, and South Korea) has suggested that there is no advantage from one or another in cardiovascular endpoints, but ARBs are associated with a better safety profile [36]. In their study [36], the primary outcomes of AMI (HR: 1.11 for ACEs vs. ARBs [95\% CI: $0.95-1.32]$ ), heart failure (HR: 1.03; 95\% CI: 0.87-1.24), stroke (HR: 1.07; 95\% CI: 0.91-1.27), or composite cardiovascular events (HR: 1.06; 95\% CI: 0.90-1.25) were not statistically different between the ACEIs and ARBs groups. Regarding secondary and safety outcomes, patients on ARBs had significantly lower risk of angioedema, cough, pancreatitis, and gastrointestinal bleeding. Therefore, these findings support preferentially prescribing ARBs over ACEIs when initiating treatment for hypertension.

In this study, prediabetes was defined as an $\mathrm{HbA}_{1 \mathrm{c}}$ of $5.7-6.4 \%$ and an FPG of $100-125 \mathrm{mg} / \mathrm{dL}$ (5.6-6.9 mmol/L) [20]. Moreover, the International Diabetes Federation has suggested that the diagnosis of prediabetes be made based on the $\mathrm{HbA}_{1 \mathrm{c}}$ since it can be measured under a non-fasting condition [37]. However, because there are some disagreements between oral glucose tolerance test (OGTT) and HbA1c, OGTT is considered more sensitive than the $\mathrm{HbA}_{1 \mathrm{c}}$ test for defining prediabetes [38]. Regarding some previous report [39] that showed positive correlation between glycated hemoglobin and $\mathrm{CD}$ or non-CD, $\mathrm{HbA}_{1 \mathrm{c}}$ can be used as alternative diagnostic tool for such assessments in patients with AMI [34]. 
This study was conducted in the era of contemporary newer-generation DESs, and multivariable and PS-adjusted analysis were performed to strengthen our results. Our study demonstrates that ACEIs and ARBs had comparable clinical outcomes in terms of POCO, all-cause death, ReMI, any revascularization, and ST during a 2-year follow-up period. In addition, similar results were observed after subgroup analysis. Thus, we speculate that our study may provide a meaningful message to interventional cardiologists who perform PCI with newer-generation DESs in patients with $\mathrm{AMI}$ and prediabetes regarding the use of ACEIs or ARBs.

\section{Limitations of the study}

This study has several limitations. First, because this study was conducted based on the level of $\mathrm{HbA}_{1 \mathrm{c}}$, the results of this study can be altered based on OGTT. Second, because this study was based on discharge medications, we did not precisely reflect drug compliance and drug-related non-cardiovascular effects of the enrolled patients during the follow-up period. Third, we could not provide correct information concerning the degree of glycemic control of the enrolled patients during the follow-up period due to deficit of detailed information of the KAMIR. Fourth, the selection of ACEIs or ARBs after PCI was left to the discretion of the physicians. This may act as an important bias in this study. Fifth, although multivariable and PS-adjusted analysis were performed to strengthen our results, the patients who were not matched at enrollment or other many clinical variables - both known and unknown - could lead to bias not accounted for by PS-adjusted analysis.

\section{Conclusions}

To conclude, in the era of contemporary newer-generation DESs, patients with AMI and prediabetes who underwent successful PCI and who received ACEIs or ARBs showed comparable clinical outcomes during the 2-year follow-up period. However, the study results should be re-evaluated in a large-scale, randomized controlled study.

\section{Acknowledgments}

The authors thank all of the clinical investigators who contributed time and effort to this study, as well as the Korea Acute Myocardial Infarction (KAMIR) Investigators.

\section{Korea Acute Myocardial infarction Registry (KAMIR) investigators}

Myung Ho Jeong, MD, Youngkeun Ahn, MD, Sung Chul Chae, MD, Jong Hyun Kim, MD, Seung-Ho Hur, MD, Young Jo Kim, MD, In Whan Seong, MD, Donghoon Choi, MD, Jei Keon Chae, MD, Taek Jong Hong, MD, Jae Young Rhew, MD, Doo-Il Kim, MD, In-Ho Chae, MD, Jung Han Yoon, MD, Bon-Kwon Koo, MD, Byung-Ok Kim, MD, Myoung Yong Lee, MD, Kee-Sik Kim, MD, Jin-Yong Hwang, MD, Myeong Chan Cho, MD, Seok Kyu Oh, MD, Nae-Hee Lee, MD, Kyoung Tae Jeong, MD, Seung-Jea Tahk, MD, Jang-Ho Bae, MD, Seung-Woon Rha, MD, Keum-Soo Park, MD, Chong Jin Kim, MD, Kyoo-Rok Han, MD, Tae Hoon Ahn, MD, Moo-Hyun Kim, MD, Ki Bae Seung, MD, Wook Sung Chung, MD, Ju-Young Yang, MD, Chong Yun Rhim, MD, Hyeon-Cheol Gwon, MD, Seong-Wook Park, MD, Young-Youp Koh, MD, Seung Jae Joo, MD, Soo-Joong Kim, MD, Dong Kyu Jin, MD, Jin Man Cho, MD, Sang-Wook Kim, MD, Jeong Kyung Kim, MD, Tae Ik Kim, MD, Deug Young Nah, MD, Si Hoon Park, MD, Sang Hyun Lee, MD, Seung Uk Lee, MD, Hang-Jae Chung, MD, Jang-Hyun Cho, MD, Seung Won Jin, MD, Myeong-Ki Hong, MD, Yangsoo Jang, MD, Jeong Gwan Cho, MD, Hyo-Soo Kim, MD and Seung-Jung Park, MD.

\section{Funding}

This research was supported by a fund (2016ER6304-02) from the Research of Korea Centers for Disease Control and Prevention.

\section{Conflict of interest: None declared}

\section{References}

1. Sinnaeve PR, Steg PG, Fox KAA, et al. Association of elevated fasting glucose with increased short-term and 6-month mortality in ST-segment elevation and non-ST-segment elevation acute coronary syndromes: the Global Registry of Acute Coronary Events. Arch Intern Med. 2009; 169(4): 402-409, doi: 10.1001/ archinternmed.2008.572, indexed in Pubmed: 19237725.

2. Kolman L, Hu YC, Montgomery DG, et al. Prognostic value of admission fasting glucose levels in patients with acute coronary syndrome. Am J Cardiol. 2009; 104(4): 470-474, doi: 10.1016/j. amjcard.2009.04.006, indexed in Pubmed: 19660596.

3. Huang Y, Cai X, Mai W, et al. Association between prediabetes and risk of cardiovascular disease and all cause mortality: systematic review and meta-analysis. BMJ. 2016; 355: i5953, doi: 10.1136/bmj.i5953, indexed in Pubmed: 27881363.

4. Eleftheriadou A, Williams S, Nevitt S, et al. The prevalence of cardiac autonomic neuropathy in prediabetes: a systematic review. Diabetologia. 2021; 64(2): 288-303, doi: 10.1007/s00125020-05316-z, indexed in Pubmed: 33164108. 
5. Giraldez RR, Clare RM, Lopes RD, et al. Prevalence and clinical outcomes of undiagnosed diabetes mellitus and prediabetes among patients with high-risk non-ST-segment elevation acute coronary syndrome. Am Heart J. 2013; 165(6): 918-925.e2, doi: 10.1016/j.ahj.2013.01.005, indexed in Pubmed: 23708162.

6. Lim HS, MacFadyen RJ, Lip GYH. Diabetes mellitus, the reninangiotensin-aldosterone system, and the heart. Arch Intern Med. 2004; 164(16): 1737-1748, doi: 10.1001/archinte.164.16.1737, indexed in Pubmed: 15364666.

7. Effects of ramipril on cardiovascular and microvascular outcomes in people with diabetes mellitus: results of the HOPE study and MICRO-HOPE substudy. Heart Outcomes Prevention Evaluation Study Investigators. Lancet. 2000; 355(9200): 253-259, indexed in Pubmed: 10675071.

8. Verdecchia P, Sleight P, Mancia G, et al. Effects of telmisartan, ramipril, and their combination on left ventricular hypertrophy in individuals at high vascular risk in the Ongoing Telmisartan Alone and in Combination With Ramipril Global End Point Trial and the Telmisartan Randomized Assessment Study in ACE Intolerant Subjects With Cardiovascular Disease. Circulation. 2009; 120(14): 1380-1389, doi: 10.1161/CIRCULATIONAHA.109.865774, indexed in Pubmed: 19770395.

9. Braga MFB, Leiter LA. Role of renin-angiotensin system blockade in patients with diabetes mellitus. Am J Cardiol. 2009; 104(6): 835-839, doi: 10.1016/j.amjcard.2009.05.015, indexed in Pubmed: 19733720.

10. Ibanez B, James S, Agewall S, et al. 2017 ESC Guidelines for the management of acute myocardial infarction in patients presenting with ST-segment elevation: The Task Force for the management of acute myocardial infarction in patients presenting with ST-segment elevation of the European Society of Cardiology (ESC). Eur Heart J. 2018; 39(2): 119-177, doi: 10.1093/eurheartj/ ehx393, indexed in Pubmed: 28886621.

11. O'Gara PT, Kushner FG, Ascheim DD, et al. 2013 ACCF/AHA guideline for the management of ST-elevation myocardial infarction: a report of the American College of Cardiology Foundation/ /American Heart Association Task Force on Practice Guidelines. J Am Coll Cardiol. 2013; 61(4): e78-e7e140, doi: 10.1016/j. jacc.2012.11.019, indexed in Pubmed: 23256914.

12. Roffi M, Patrono C, Collet JP, et al. 2015 ESC Guidelines for the management of acute coronary syndromes in patients presenting without persistent ST-segment elevation: Task Force for the Management of Acute Coronary Syndromes in Patients Presenting without Persistent ST-Segment Elevation of the European Society of Cardiology (ESC). Eur Heart J. 2016; 37(3): 267-315, doi: 10.1093/eurheartj/ehv320, indexed in Pubmed: 26320110.

13. Amsterdam EA, Wenger NK, Brindis RG, et al. 2014 AHA/ /ACC Guideline for the Management of Patients with Non-ST-Elevation Acute Coronary Syndromes: a report of the American College of Cardiology/American Heart Association Task Force on Practice Guidelines. J Am Coll Cardiol. 2014; 64(24): e139-e228, doi: 10.1016/j.jacc.2014.09.017, indexed in Pubmed: 25260718.

14. McMurray J, Solomon S, Pieper K, et al. The effect of valsartan, captopril, or both on atherosclerotic events after acute myocardial infarction: an analysis of the Valsartan in Acute Myocardial Infarction Trial (VALIANT). J Am Coll Cardiol. 2006; 47(4): 726-733, doi: 10.1016/j.jacc.2005.09.055, indexed in Pubmed: 16487836.

15. Dickstein K, Kjekshus J. Effects of losartan and captopril on mortality and morbidity in high-risk patients after acute myocardial infarction: the OPTIMAAL randomised trial. Lancet. 2002; 360(9335): 752-760, doi: 10.1016/s0140-6736(02)09895-1.
16. Choi SY, Choi BG, Rha SW, et al. Angiotensin-converting enzyme inhibitors versus angiotensin II receptor blockers in acute ST-segment elevation myocardial infarction patients with diabetes mellitus undergoing percutaneous coronary intervention. Int J Cardiol. 2017; 249: 48-54, doi: 10.1016/j.ijcard.2017.08.030, indexed in Pubmed: 28867244.

17. Lv X, Zhang Y, Niu Y, et al. Comparison of angiotensin-converting enzyme inhibitors and angiotensin II receptor blockers on cardiovascular outcomes in hypertensive patients with type 2 diabetes mellitus: A PRISMA-compliant systematic review and meta-analysis. Medicine (Baltimore). 2018; 97(15): e0256, doi: 10.1097/MD.0000000000010256, indexed in Pubmed: 29642146.

18. Kim JuH, Chae SC, Oh DJ, et al. Multicenter Cohort Study of Acute Myocardial Infarction in Korea-Interim Analysis of the Korea Acute Myocardial Infarction Registry-National Institutes of Health Registry. Circ J. 2016; 80(6): 1427-1436, doi: 10.1253/ circj.CJ-16-0061, indexed in Pubmed: 27118621.

19. Grech $\mathrm{ED}$. $\mathrm{ABC}$ of interventional cardiology: percutaneous coronary intervention. II: the procedure. BMJ. 2003; 326(7399): 1137-1140, doi: 10.1136/bmj.326.7399.1137, indexed in Pubmed: 12763994.

20. American Diabetes Association. Standards of medical care in diabetes: 2010. Diabetes Care. 2010; 33 Suppl 1: S11-S61, doi: 10.2337/dc10-S011, indexed in Pubmed: 20042772.

21. Garcia-Garcia HM, McFadden EP, Farb A, et al. Academic Research Consortium. Standardized End Point Definitions for Coronary Intervention Trials: The Academic Research Consortium-2 Consensus Document. Circulation. 2018; 137(24): 2635-2650, doi: 10.1161/CIRCULATIONAHA.117.029289, indexed in Pubmed: 29891620.

22. Kim YH, Her AY, Jeong MHo, et al. Impact of stent generation on 2-year clinical outcomes in ST-segment elevation myocardial infarction patients with multivessel disease who underwent culprit-only or multivessel percutaneous coronary intervention. Catheter Cardiovasc Interv. 2020; 95(2): E40-E55, doi: 10.1002/ ccd.28440, indexed in Pubmed: 31423723.

23. Bundhun PK, Wu ZiJ, Chen MH. Is there any significant difference in stent thrombosis between sirolimus and paclitaxel eluting stents?: A systematic review and meta-analysis of randomized controlled trials. Medicine (Baltimore). 2016; 95(5): e2651, doi: 10.1097/MD.0000000000002651, indexed in Pubmed: 26844487.

24. Scheen AJ. Renin-angiotensin system inhibition prevents type 2 diabetes mellitus. Part 2. Overview of physiological and biochemical mechanisms. Diab Metab. 2004; 30(6): 498-505, doi: 10.1016/s1262-3636(07)70147-7.

25. Cheng J, Zhang W, Zhang X, et al. Effect of angiotensin-converting enzyme inhibitors and angiotensin II receptor blockers on all-cause mortality, cardiovascular deaths, and cardiovascular events in patients with diabetes mellitus: a meta-analysis. JAMA Intern Med. 2014; 174(5): 773-785, doi: 10.1001/jamainternmed.2014.348, indexed in Pubmed: 24687000.

26. Haller H, Ito S, Izzo JL, et al. Olmesartan for the delay or prevention of microalbuminuria in type 2 diabetes. $\mathrm{N}$ Engl J Med. 2011; 364(10): 907-917, doi: 10.1056/NEJMoa1007994, indexed in Pubmed: 21388309.

27. Marre M, Lievre M, Chatellier G, et al. Effects of low dose ramipril on cardiovascular and renal outcomes in patients with type 2 diabetes and raised excretion of urinary albumin: randomised, double blind, placebo controlled trial (the DIABHYCAR study). BMJ. 2004; 328(7438): 495, doi: 10.1136/bmj.37970.629537.0D, indexed in Pubmed: 14960504. 
28. Wang $\mathrm{K}, \mathrm{Hu} \mathrm{J}$, Luo T, et al. Effects of angiotensin-converting enzyme inhibitors and angiotensin II receptor blockers on allcause mortality and renal outcomes in patients with diabetes and albuminuria: a systematic review and meta-analysis. Kidney Blood Press Res. 2018; 43(3): 768-779, doi: 10.1159/000489913, indexed in Pubmed: 29794446.

29. Zidek W, Schrader J, Lüders S, et al. Ramipril-based versus diuretic-based antihypertensive primary treatment in patients with pre-diabetes (ADaPT) study. Cardiovasc Diabetol. 2012; 11: 1, doi: 10.1186/1475-2840-11-1, indexed in Pubmed: 22230104.

30. Min SeH, Kong SH, Lee JE, et al. Association of angiotensin-II levels with albuminuria in subjects with normal glucose metabolism, prediabetes, and type 2 diabetes mellitus. J Diabetes Complications. 2017; 31(10): 1499-1505, doi: 10.1016/j.jdiacomp.2017.07.002, indexed in Pubmed: 28797632.

31. Zhang C, Knudson JD, Setty S, et al. Coronary arteriolar vasoconstriction to angiotensin II is augmented in prediabetic metabolic syndrome via activation of AT1 receptors. Am J Physiol Heart Circ Physiol. 2005; 288(5): H2154-H2162, doi: 10.1152/ ajpheart.00987.2004, indexed in Pubmed: 15653764.

32. Strauss MH, Hall AS. Angiotensin receptor blockers may increase risk of myocardial infarction: unraveling the ARB-MI paradox. Circulation. 2006; 114(8): 838-854, doi: 10.1161/CIRCULATIONAHA.105.594986, indexed in Pubmed: 16923768

33. Verma S, Strauss M. Angiotensin receptor blockers and myocardial infarction. BMJ. 2004; 329(7477): 1248-1249, doi: 10.1136/ bmj.329.7477.1248, indexed in Pubmed: 15564232.
34. Kok MM, von Birgelen C, Sattar N, et al. Prediabetes and its impact on clinical outcome after coronary intervention in a broad patient population. EuroIntervention. 2018; 14(9): e1049-e1056, doi: 10.4244/EIJ-D-17-01067, indexed in Pubmed: 29313817.

35. Yang JH, Hahn JY, Song YB, et al. Angiotensin receptor blocker in patients with ST segment elevation myocardial infarction with preserved left ventricular systolic function: prospective cohort study. BMJ. 2014; 349: g6650, doi: 10.1136/bmj.g6650, indexed in Pubmed: 25398372.

36. International Expert Committee. International Expert Committee report on the role of the $\mathrm{A} 1 \mathrm{C}$ assay in the diagnosis of diabetes. Diabetes Care. 2009; 32(7): 1327-1334, doi: 10.2337/ dc09-9033, indexed in Pubmed: 19502545.

37. Iskandar S, Migahid A, Kamal D, et al. Glycated hemoglobin versus oral glucose tolerance test in the identification of subjects with prediabetes in Qatari population. BMC Endocr Disord. 2019; 19(1): 87, doi: 10.1186/s12902-019-0412-1, indexed in Pubmed: 31438915.

38. Silbernagel G, Grammer TB, Winkelmann BR, et al. Glycated hemoglobin predicts all-cause, cardiovascular, and cancer mortality in people without a history of diabetes undergoing coronary angiography. Diabetes Care. 2011; 34(6): 1355-1361, doi: 10.2337/dc10-2010, indexed in Pubmed: 21515847.

39. Kowalczyk J, Mazurek M, Zielinska T, et al. Prognostic significance of HbA1c in patients with AMI treated invasively and newly detected glucose abnormalities. Eur J Prev Cardiol. 2015; 22(6): 798-806, doi: $10.1177 / 2047487314527850$, indexed in Pubmed: 24618476. 